\title{
WHAT IT TAKES TO SET UP TRAVEL HEALTH SERVICES: A REVIEW FROM COUNTRIES WITH ESTABLISHED SERVICE
}

\author{
Muhammad Haikal Bin Ghazali, Shamsul Azhar Bin Shah and Mohd Rizal Bin Abd Manaf \\ Department of Community Health, Universiti Kebangsaan Malaysia, Jalan Yaacob Latif, Bandar Tun Razak, 56000 \\ Cheras, Kuala Lumpur, Malaysia \\ Corresponding author: \\ Muhammad Haikal Bin Ghazali \\ E-mail: drhaikalghazali@gmail.com
}

\begin{abstract}
As air travelling now becomes cheaper and available to almost all people of any walk of life, travelling across international borders is fast becoming a lifestyle of many. Having travel health service as part of health care services is important to address the issues of travel related illnesses among travellers. However, lacks of published guidelines pertaining to travel health service rendering many countries to overlook its importance. The aim of this paper is to review published literatures and authoritative websites on the components needed to develop guideline to establish travel health services. A systematic literature search was done using pre-specified keywords for literatures published between years 2000 - 2016. Literatures written in English and fully accessible were all included. No exclusion criteria was set before the search. Online authoritative websites pertaining to travel health were also referred. A total of six literatures ranging from expert opinion, review paper and original study, together with three authoritative websites related to travel health were reviewed. Among the important components needed to be considered for developing the guideline for establishing travel health services are to prioritise pre-travel health service, to set up specialised travel health clinic, to produce travel health/medicine specialist, to emphasize on continuous education and training of the practitioners and to apply multiagency and multidisciplinary approach with adequate fund for research in travel health. As a conclusion, policy makers should prioritise and select the most important components in developing guideline for travel health service.
\end{abstract}

Keywords: Travel health service, travel medicine, guideline development

\section{INTRODUCTION}

International travelling is now no longer an activity of only wealthy individuals. 'Everybody can fly' has now been a motto of the people rather than an airline company. The increase in the air travelling facilities at a much more affordable individual cost than before, the change in business trend whereby cross-countries deal becomes more common, and the fact that international travelling is becoming more of a lifestyles nowadays have all contributed to the increase in international air travelling all over the world ${ }^{1}$.

Knowing that travelling is closely related to the spread of diseases ${ }^{2}$, travel health therefore becomes an important integral aspect of services need to be offered to those travellers. Among the well-emphasized components of travel health services is the pre-travel health assessment comprising of health consultation pre-travelling, risk assessment, vaccination and chemoprophylaxis ${ }^{3}$. These four sub-components are fundamental for preventive strategies because pre-travel preparation will determine the well-being of travellers before, during and after travel ${ }^{4}$.
As many countries are still lacking of travel health services despite the urgent need, therefore a careful and effective planning into incorporating the said service in the current healthcare system need to be commenced. Developing guideline forms one of the three crucial things in forming highly effective healthcare services following priority setting and evidence review ${ }^{5}$. Whilst WHO has outlined that there are at least six type of guidelines that can be adopted for a healthcare services, those types of guidelines needed to be carefully selected as it will determine the method and time frame for its development ${ }^{6}$.

This paper thus will review published literatures relevant to travel health services guideline development with the aims to determine the components related to guideline development for establishing travel health services and also to determine the effective ways of implementing the guidelines across countries and its related factors.

\section{METHODS}

Concepts and definition

The concept of travel health service is defined based on the definition set by the Public Health 
Agency of Canada (PHAC). They define it as a service concerns with the promotion of health and respect for the peoples, cultures and environment of regions being visited in addition to the prevention of disease or other adverse health outcomes in the international traveller as well as any impact on the health of the local population ${ }^{7}$.

Guidelines in this paper is defined within public health concern as stated by the National Institute for Health and Care Excellence (NICE) available in its official website. It states that a public health guideline should recommend on local interventions that can aid prevent diseases or improve health, which may focus on a particular health topic, a particular population or a particular setting. Therefore, the concept of this review will look into the process of developing effective guidelines pertaining to the establishment of health services (intervention to improve health) relevant to taking care of international travellers (population).

\section{Search Strategy}

Literatures reviewed were those published between years 2000 - 2016 and according to PRISMA statements ${ }^{8}$. Since there were limited articles describing on guidelines for travel health or medicine services, no specific exclusion criteria were set before the search. Articles in the form of review articles, letter to editor, expert opinion and original article deemed relevant to the topic which were written in English and accessible as full article were included. The keywords used were [travel health OR travel medicine] AND [guidelines OR policy] with and without [development]. Different combination were used to optimise the search results. Google scholar, PubMed, Ovid Medline, EBSCOhost and SCOPUS were searched.

Manual search from the citations of the literatures obtained via electronic search was also done to add up to the overall search results. Besides literatures, online websites for public health guidelines development such as from NICE and WHO were also referred. Travel health services from various countries websites were also included. A total of 17 records were initially retrieved and after duplicates were removed, 11 were screened. There were three records excluded after screening due to inaccessibility for full texts. And finally six articles were included for final analyses. The flow of the search strategy is summarised in figure 1 .

\section{RESULTS}

Of the six published articles included for the final review, five were retrieved via electronic database with one cross referencing which yield one article. There are two review articles, one letter to editor, one original study, and two guidelines. Those articles were analysed thematically looking into components of travel health services which have to be set up, priorities of the service either at the ministries or clinic level, and also the level of effectiveness when the service being implemented according to the available guideline.

The themes were chosen following an in-depth discussion with the experts on how to set up a new health service in countries lacking of the said service. Therefore, the chosen themes are all focusing on delivering salient points to policy makers to help them understand the important elements need to be considered before setting up a travel health service.

There are three official websites reviewed with the same themes as done with the articles. Those are the websites developed by the Public Health Agency of Canada (PHAC), the World Health Organization (WHO) thru its International Travel and Health chapter, and the United States Centres for Disease Control and Prevention (US CDC). The main findings of the search results are summarised in table 1.

\section{Components of travel health services}

There are four out six of the reviewed articles and all websites put emphasis on the pre-travel health services with one article stated about the importance of post travel health services ${ }^{9}$. All three websites discussed about the need of post travel health services. Among the important subcomponent of pre-travel health services mentioned by either the articles or websites are: pre travel-health consultation, pre-travel health risk assessment and pre-travel vaccination ${ }^{7,9-12}$, provision ofchemoprophylaxis pre-travelling ${ }^{9-11}$, and provision of medical kit and toilet items as according to the WHO and US CDC.

There are three out six articles and one website suggested for a travel health services to be effectively delivered, it must be done in a specialised and dedicated travel health clinics $^{7,}, 9$, 11,12 . On the importance of having online database or websites to complete a travel health service for the ease of both consumers and practitioners, there are two articles discuss specifically on this ${ }^{12,13}$. There is one article suggested for travel health service to have practice guidelines for the benefit of the practitioners $^{14}$.

\section{Priorities in delivering travel health services}

There are a few priorities a travel health service should give emphasis on when dealing with travellers to ensure optimal service is delivered and achieve its purposes. There is one article and 
one website talk on the importance of emphasizing on the health education of the travellers to promote for behavioural change ${ }^{11}$. Having qualified and adequately trained travel health/medicine specialists particularly to deal with complex case is deemed necessary by two articles and one website w, $^{\text {9, } 11}$.

Priorities should also be given to continuous training and knowledge update of the practitioners at all level with regard to knowledge about travel related diseases and the use of guidelines and databases according to three articles ${ }^{10,13,14}$. The need of special care to those with special needs in travel such as those with chronic diseases, pregnant ladies and infant travellers are also seen as a priority by the US CDC, while WHO put a priority to gain a multiagency collaboration in setting up a travel health service.

\section{Keys to effective implementation of travel health service}

There are several keys to effective implementation of travel health services. An article has suggested that to be effective, travel health service should be approached on individual basis rather than cumulative approach ${ }^{11}$. The same article also extensively talk on improving the knowledge, attitude and practice (KAP) of the travellers as an important determinant for an effective travel health service to take place. There is one article and a website(PHAC website) seeing educating the travel health care providers to maintain competency and effectiveness of travel health services ${ }^{7,11}$.

Majority of the reviewed articles and websites put multidisciplinary and multiagency approach as the key to effective delivery of travel health services, including to incorporate travel agency and general practitioner as the stakeholders ${ }^{10,12,}$ ${ }^{14}$. Good accessibility as well as good promotional strategies of the service are deemed as keys to effective implementation of travel health services by two articles and one website ${ }^{9,13}$. The role of research either client oriented, provider oriented or system oriented is seen as key by both PHAC and $\mathrm{WHO}^{7}$. Lastly, the US CDC sees adequate funding as one of the keys to an effective travel health service delivery.

\section{DISCUSSION}

\section{Developing public health guidelines}

Both NICE and WHO describe the process of developing public health guidelines very similarly. The methodologymainly involve identifying priorities, formulating key questions (Population, Intervention, Comparison and Outcomes, PICO), comprehensive search of scientific evidence, consultation with stakeholders as well as dissemination and implementation ${ }^{6,15}$. It is an ongoing process which needs constant reviewing and updating to ensure its relevance and effectiveness over time ${ }^{16,17}$. Hence, the same concept should also be applied to develop the guideline for travel health services. The essential components to be considered in the development of guidelines specific to travel health will thus be discussed comprehensively.

\section{Prioritising the pre-travel component}

As has been presented in the result section, majority of the literatures and all the reviewed websites put emphasis on the pre-travel health service as the main component of the travel health service itself. The main sub-components that should be in the pre-travel scope are the: pre-travel health and environmental risk assessment (the latter refers to the region to be visited), health consultation and education, vaccination and the provision of chemoprophylaxis particularly to those travellers travelling to malaria endemic regions ${ }^{7,9-12}$. The service could be extended to the provision of medical kit and toilet items on travellers going to less developed countries.

Pre-travel health service is deemed as the most essential integral part of travel health service because the sub-components within it will ensure the well-being of the travellers before and during the travel periods ${ }^{18}$. Freedman et.al 2016 has specifically stated that health education that form as part of the pre-travel health consultation should be effectively carried out by the travel health care provider to promote for behavioural change among the travellers. While post-travel health impacts are the ones that make up the statistics, it can be prevented thru proper and adequate pre-travel health education delivered by appropriate practitioners in a correct setting ${ }^{19}$, 20.

Post-travel health service, though has not been mentioned in as many literatures as the pretravel part, deemed important by all the three authoritative websites. Post-travel health service deals mainly with symptoms recognition on the returning travellers as well as screening those asymptomatic travellers returning high risk areas or indulge in high-risk activities ${ }^{21}$. However, as compared to the pre-travel component, the posttravel component can be managed equally effective by other medical disciplines such as the general practitioners or the infectious diseases speciality ${ }^{22}$. Therefore, for health care policy makers to start formulating travel health service in the existing health care system, prioritising pre-travel health services and later incorporating the post-travel component to complete the service will make the introduction easier to set up. 
There also comes the need for physical components for a pre-travel health services to be delivered efficiently. The need for dedicated and specialised setting for travel health service i.e travel health clinic equipped with travel health related online services or databases (e.g TRAVAX) will help the practitioners to manage travellers in a more conducive and convincing environment ${ }^{11}$, 13, 23

\section{Emphasising on producing the experts}

The development of guideline specific to travel health should also put emphasis on the training and education of the travel health care providers. Freedman et al. 2016 and Hill et al. 2006 are of the same opinion that there should be travel health/medicine specialists to be produced via training at par with other clinical specialists. The travel health/medicine specialists are needed when dealing with complex cases in travel health aspect such as travellers with chronic diseases, disabilities, pregnancy or even infant travellers. This suggestion is in accordance with the recommendation by the Public Health Agency of Canada ${ }^{7}$. Hill et al. 2006 for example has described that travel health practitioners should even be encouraged to be formally trained to obtain membership from travel health and medicine governing bodies such as the International Society of Travel Medicine (ISTM).

Besides that, continuous education and training should also be extended to all other travel health care providers at all level such as the nurses, medical attendants and pharmacists ${ }^{10,13,14}$. The training and education of the travel health care providers should aim to update the knowledge with regards to travel related illness, risk assessments and health education delivery to clients to continuously improve the service. A study done in Switzerland and Germany looking into the impact of lacking in travel health education among health care providers had demonstrated that while $90 \%$ of general practitioners in both countries gave travel health advice to incoming travellers, but only about $11 \%$ (Swiss) and 1\% (Germany) practitioners gave correct advice ${ }^{24}$. Apart from that, training and education of travel health care providers should also covers on the use of databases ${ }^{13}$ and practice guidelines ${ }^{14}$ to improve service delivery.

\section{Ensuring effective implementation of travel health service}

It is important to ensure that every health care services provided to the public achieve its objectives to determine its effectiveness. The same goes to travel health service. Freedman et al. 2006 has outlined three important keys to ensure the successful implementation of travel health service. The first one to approach the service on individual basis rather than cumulative ones. It means, travel health case management should look at a traveller as a unique individual with unique needs different from other travellers even though they come for the service seeking advice to go abroad to the same place. This is in accordance to a recommendation by Leggat 2006 that emphasised individual approach in performing travel risk assessment ${ }^{25}$.

Freedman et al. 2006 has also suggested that clients' good perception, knowledge, attitude and practice (KAP) towards travel health could ensure the success of implementation of travel health service. This is understandable because with good perception and KAP, the uptake of the provided services will be better, hence no resources will be wasted $^{26}$. Another key to successful implementation outlined by Freedman in which in accordance to PHAC is that continuous training and education provided to the travel health care providers should be in place. This is important to sustain the services and gain public confidence to continuously use the services ${ }^{7,27}$.

Besides that, travel health guideline developers should also think of collaborating with other agencies and disciplines that are close related to travel industry. Multiagency and multidisciplinary approach in delivering travel health services are deemed very important by majority of the reviewed articles and websites. In this regard, Podolsky 2006 has described that the multiagency collaboration should include travel agencies, because travel agents know better about their clients and also the place to be visited. This information will add value in term of risk assessments as well as helping increase the uptake of travel health service when travel agencies themselves are closely related to travel health care providers. Multidisciplinary approach is well emphasized by the US CDC and WHO in which medical disciplines such as infectious diseases, tropical medicines, epidemiology and even dermatology (skin manifestation is common among returning travellers) should work closely in travel health services for ease of referral and consultations, for both clients and practitioners.

Another key to successful and effective implementation of travel health services is to ensure that the accessibility of travel health facilities and services are good ${ }^{9,13}$. Accessibility of travel health services could be in the form of adequate numbers of travel health clinics or relevant facilities at the appropriate locations, adequate number of staffs and the services must be made known to public i.e promotion of services through multi-channel approach.

Finally, the role of research and adequate funding are also important to ensure travel health services continuously relevant to travelling public. Both the PHAC and WHO encourages 
travel health care providers to conduct more researches in understanding the needs of travelling public, improving services, evaluation of services as well as epidemiological research of travel related diseases ${ }^{3,7}$. Adequate funding is deemed important by the USCDC because to sustain such service at par with other health care services, a lot need to be done in term of sustaining the facilities, conducting research, provision of training and education for the providers as well as travel health promotional activities.

The strength of this review is it incorporates multi sources of information ranging from expert opinions to original study, with additional guidance from authoritative travel health websites. The limitation lies in the lack of recent published literatures pertaining to travel health guidelines. As mentioned before, this review includes letter to editor and review article in which rated as less strong in evidence based medicine. Besides, the available original studies are mainly from the countries with established travel health servicesequipped with good resources, thus this paper must be referred cautiously by policy makers from those countries with inadequate resources.

\section{CONCLUSION AND RECOMMENDATION}

As a conclusion, those points and criteria discussed above should help the policymakers on developing the guidelines for setting up travel health services. As a start, pre-travel health service should be in place with adequate physical facilities and run by trained and knowledgeable providers. Travel health services should also be a multiagency responsibility, with ongoing research and adequate fund to support it for sustainability. It is recommended that countries with no travel health service to collaborate and learn from those countries with established travel health services, the likes of Canada and US. Travel health care model from those established countries can be adopted to local settings with continuous effort for improvement in the future.

Figure 1: Flow chart of article search strategy according to PRISMA statements.
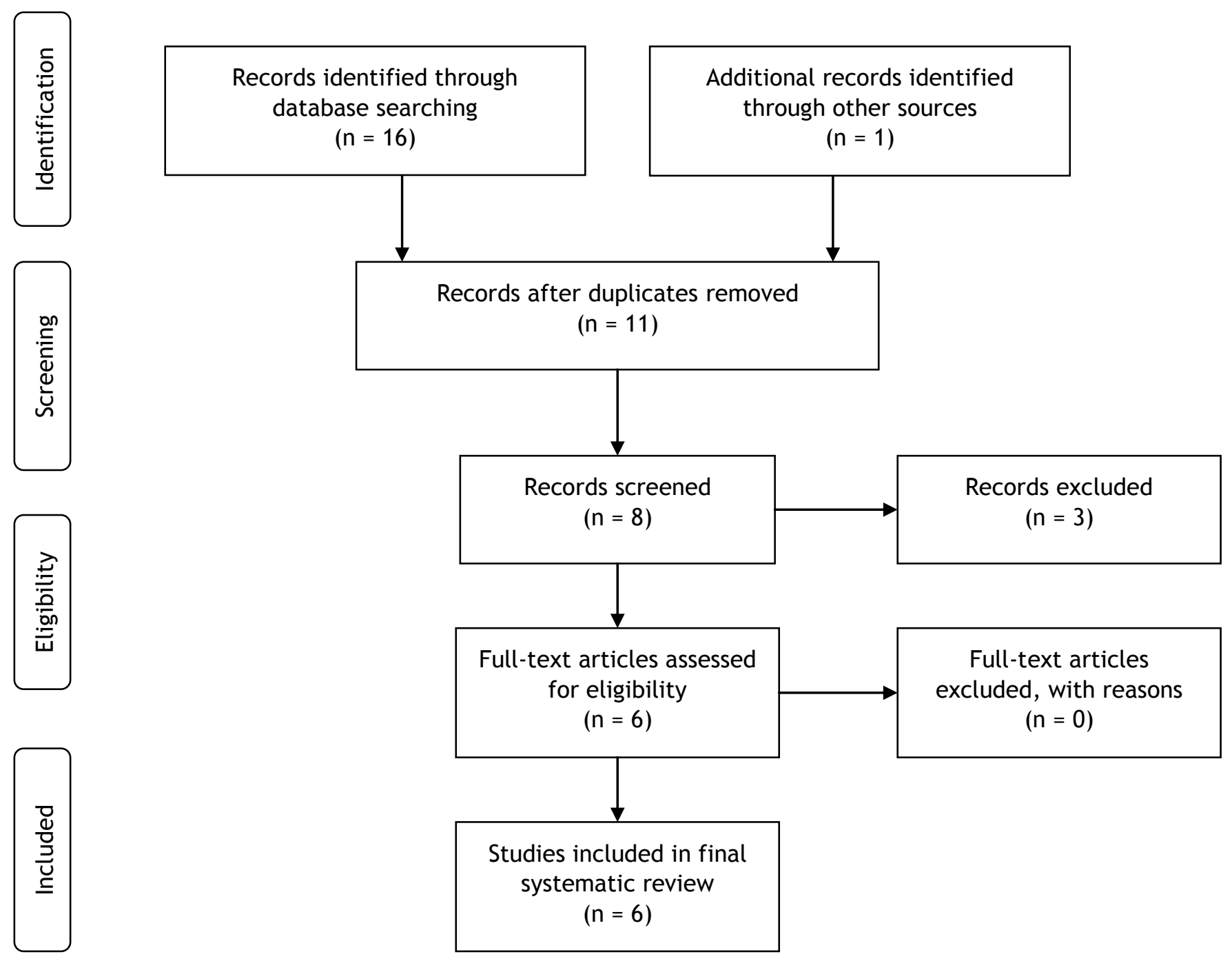
Table 1: Summary of search results described thematically

\section{First author; Type of article}

year

(country)

Freedman et Review article

al. 2016 (UK)
Components of travel health services mentioned or Priorities mentioned or discussed discussed
1. Structured approach of pre-travel medical consultation comprising of

a. Risk assessment

b. Stand in office intervention (for immunization and chemoprohylaxis preparation)

c. Focused education before trip

2. Pre-travel vaccination

a. Routine vaccination should be regularly verified and updated

3. Chemoprohylaxis

a. A few illnesses requiring chemoprophylaxis such as malaria must be taken seriously by physician when giving pre-travel consultation.
1. Education and prevention should be focused on travellers visiting friend and relative (VFR)

2. Travel health specialist is needed to cater high-risk travellers such as immunocompromised, chronic diseased etc

3. Education during consultation should remind on behavioural change and self-treatment strategies.
Effectiveness of the

implementation

\begin{tabular}{ll}
\hline Podolsky Letter to editor \\
2006 & \\
(Canada)
\end{tabular}

Specialised travel health/medicine clinics for pre and post travel health service

Provide specialized consultation and immunization other that ordinary family GP

The existence of websites promoting the service to community and related stakeholders especially travel agencies.
1. Individualized preventive and medical strategies

2. Travellers must be equipped with adequate knowledge and substantial behavioural change

3. Healthcare providers should be trained at all level (nurses, medical officers and specialist etc)
Close collaboration between travel health/medicine and travel agencies for travellers' referral pre and post travel.
1. Travel health/medicine clinic provider need to be proactive promoting their service to community and travel agencies

2. Frequent and scheduled update of knowledge to both service providers and travel agency providers.

3. Integrating travel agent personnel in travel health/medicine clinic

1. Travel health service should be readily accessible in term of where to locate the clinic and adequacy in numbers.

2. Multidisciplinary approach to ensure pre and post travel health care can be delivered holistically. This include effective referral system 
Letter (offline database) for pre-travel assessment

b. The use of Global Infectious Disease and Epidemiology Network (online) for post-travel assessment.

\section{provider}

2. International communication and information sharing pertaining to cross-borders outbreaks

3. Avoid contradictory information of travel related diseases and their management among clinician and publics

\begin{tabular}{ll}
\hline $\begin{array}{l}\text { Websites; } \\
\text { (country) }\end{array}$ & URL (topic) \\
\hline Public & http://www.pha \\
Health & c-aspc.gc.ca \\
Agency of & (Guidelines for \\
Canada & the Practice of \\
(Canada) & Travel Medicine
\end{tabular}

\begin{tabular}{ll}
\hline World Health & http://www.who \\
Organization & .int/ith/en/ \\
(WHO) & (International \\
& Travel and \\
& Health \\
& Guidelines)
\end{tabular}

a. Focusing on ill returning travellers
1. Ensuring top quality of pretravel health services thru providing qualified practitioner

a. Importance of eliminating barrier for public to access the service: system level (uninsured service may incur additional cost to travellers), client level (inadequate risk perception,

knowledge and attitude), provider level (inadequate knowledge and incorrect service delivery model)

b. Sub-component should consist of risk assessment, education and vaccination

2. Specialised travel health/medicine clinics for pre and post travel health service

1. Pre-travel health service comprising of:

a. Consultation

b. Health risk assessment

c. Provision of medical kit and toilet items

d. Insurance coverage

e. Vaccination
2. Well-equipped travel health

1. Appropriate vaccination should be given to every travellers travelling to endemic prone countries, especially those considered as high risk travellers. up and governing travel health services. specialised clinics.
2. A governing body to coordinate information to ensure accuracy and avoid contradiction.

1. Continuous research to understand and eliminate the barriers from accessing travel health service.

2. Maintenance of competency of the practitioner thru continuous education and training
2. Multiagency cooperation to set

\begin{tabular}{|c|c|c|c|c|}
\hline $\begin{array}{l}\text { Centres for } \\
\text { Disease } \\
\text { Control and } \\
\text { Prevention, }\end{array}$ & $\begin{array}{l}\text { http://wwwnc.c } \\
\text { dc.gov/travel/yel } \\
\text { lowbook (Yellow } \\
\text { Book) }\end{array}$ & $\begin{array}{l}\text { 1. Pre-travel health service comprising of: } \\
\text { a. Consultation } \\
\text { b. Health risk assessment } \\
\text { c. Provision of medical kit and toilet }\end{array}$ & $\begin{array}{l}\text { 1. Special care should be given to } \\
\text { travellers with special needs } \\
\text { such as chronic illnesses or } \\
\text { disabilities, pregnant ladies, }\end{array}$ & $\begin{array}{l}\text { 1. Continuous dissemination of } \\
\text { information using multi- } \\
\text { channel approach to reach } \\
\text { travellers }\end{array}$ \\
\hline
\end{tabular}

Expanding research to est travel health care to clients

2. Multinational communication in term of disease surveillance and data collection

3. Emphasis on multiagency collaboration to ensure effective care and management of travel related diseases and injuries. 
CDC (USA)

\section{items}

d. Vaccination

e. Provision of chemoprophylaxis

2. Post travel evaluation including screening for asymptomatic travellers. infants etc.

2. Improving travellers' perception of risk associated with travel to increase uptake of travel health service.
2. Adequate funds and budget to sustain travel health services

3. Empowering GPs to provide out-of-government travel health services.

4. Multiagency approach to ensure expansion of services and broaden networks. 


\section{REFERENCES}

1. World Tourism Organization. World tourism barometer 2015.

2. Schlagenhauf $P$, Santos-O'Connor F, Parola P. The practice of travel medicine in Europe. Clin Microbiol Infect 2010; 16(3):203-8.

3. World Health Organization. Consultation on strategies for internatonal travel and health (ITH): Meeting report. Netherland: International Travel and Health (ITH), 2013.

4. Centers for Disease Control and Prevention. Health information for international travel 2014: The yellow book. USA: Oxford University Press; 2013.

5. Eden J, Wheatley B, McNeil B, Sox H. Knowing what works in health care: a roadmap for the nation: National Academies Press; 2008.

6. World Health Organization. Handbook for guideline development. Geneva: World Health Organization; 2014.

7. Public Health Agency of Canada. Guidelines for the practice of travel medicine. Canada: 2009 Contract No.: 8.

8. Moher D, Liberati A, Tetzlaff J, Altman DG, Group P. Preferred reporting items for systematic reviews and meta-analyses: the PRISMA statement. PLoS medicine 2009; 6(7):e1000097.

9. Hill DR, Ericsson CD, Pearson RD, Keystone JS, Freedman DO, Kozarsky PE, DuPont HL, Bia FJ, Fischer PR, Ryan ET. The practice of travel medicine: guidelines by the Infectious Diseases Society of America. Clin Infect Dis 2006; 43(12):1499-539.

10. Zuckerman JN. Travel medicine. BMJ 2002; 325(7358):260-4.

11. Freedman DO, Chen LH, Kozarsky PE. Medical considerations before international travel. $\mathrm{N}$ Engl J Med 2016; 2016(375):247-60.

12. Podolsky G. Travel Medicine and the Travel Industry. Wilderness Environ Med 2006; 17(1):71-2.

13. Keystone JS, Kozarsky P, Freedman DO, Nothdurft HD, Connor BA. Travel medicine: Elsevier Health Sciences; 2012.

14. d'Acremont V, Burnand B, Ambresin A-E, Genton B. Practice guidelines for evaluation of fever in returning travelers and migrants. J Travel Med 2003; 10(suppl 2):s25-s45.

15. National Institute for Health and Care Excellence. Methods for the development of
NICE public health guidance (third edition). Process and methods. UK 2012.

16. Schünemann HJ, Fretheim A, Oxman AD. Improving the use of research evidence in guideline development: 1. Guidelines for guidelines. Health Research Policy and Systems 2006; 4(1):1.

17. Thant Z, Than M, Shamsul B, Wai P, Htun H, Osman A. Focusing health equity, efficiency and health maximization policy review. Malaysian Journal of Public Health Medicine 2013; 13(1):64-71.

18. Chen LH. The pre-travel consultation. CDC Health Information for International Travel 2014: The Yellow Book 2013:26.

19. Wadhwaniya S, Hyder AA. Pre-Travel Consultation Without Injury Prevention Is Incomplete. Journal of travel medicine 2013; 20(4):217-20.

20. Hassali $M$, Saleem F, Shafie A, Aljadhey $H$, Chua G, Masood I, Haq N. Perception towards health promotion activities: findings from a community survey in the state of Penang, Malaysia. Malaysian Journal of Public Health Medicine 2012; 12(2):6-14.

21. Hill DR. Health problems in a large cohort of Americans traveling to developing countries. J Travel Med 2000; 7(5):259-66.

22. Newman-Klee C, D'Acremont V, Newman CJ, Gehri M, Genton B. Incidence and types of illness when traveling to the tropics: a prospective controlled study of children and their parents. The American journal of Tropical medicine and hygiene 2007; 77(4):764-9.

23. Shaw M. Running a travel clinic. Travel Med Infect Dis 2006; 4(3):109-26.

24. Hatz C, Krause E, Grundmann H. Travel advice: a study among Swiss and German general practitioners. Trop Med Int Health 1997; 2(1):6-12.

25. Leggat PA. Risk assessment in travel medicine. Travel Med Infect Dis 2006; 4(3):127-34.

26. Pfeil A, Mütsch M, Hatz C, Szucs T. A crosssectional survey to evaluate knowledge, attitudes and practices (KAP) regarding seasonal influenza vaccination among European travellers to resource-limited destinations. BMC Public Health 2010; 10(1):402.

27. Azhar A, Rahman MM, Arif MT. Satisfaction on primary health care services in sarawak, malaysia: evidence from a cross-sectional 
